\title{
Differential expression of Oct3/4 in human breast cancer and normal tissues
}

\author{
FENG-QI ZHAO ${ }^{1}$, YOGI MISRA ${ }^{1}$, DA-BIAO LI ${ }^{1}$, MARILYN P. WADSWORTH ${ }^{2}$, \\ DAVID KRAG $^{3}$, DONALD WEAVER ${ }^{2}$, JOSEPH TESSITORE $^{2}$, DA-WEI LI $^{4}$, \\ GUO ZHANG $^{1}$, QING TIAN ${ }^{1}$ and KATIE BUSS ${ }^{1}$ \\ Departments of ${ }^{1}$ Animal and Veterinary Sciences, ${ }^{2}$ Pathology, ${ }^{3}$ Surgery, \\ ${ }^{4}$ Microbiology and Molecular Genetics, University of Vermont, Burlington, VT 05405, USA
}

Received October 23, 2017; Accepted March 22, 2018

DOI: 10.3892/ijo.2018.4341

\begin{abstract}
Oct3/4, a transcription factor specifically expressed in mammalian totipotent embryonic stem and germ cells, has a critical role in the regulation and maintenance of pluripotency and self-renewal. However, reactivation of Oct $3 / 4$ expression is observed in several human breast cancer cell lines, but not in non-malignant cells. To examine Oct $3 / 4$ expression in human primary breast carcinomas and normal breast tissues, we obtained breast tumor tissues from 28 patients and normal breast tissues from 9 women. According to quantitative polymerase chain reaction, all of the tumor tissues, irrespective of tumor type or clinicopathological status, expressed Oct $3 / 4$ mRNA at 10- to 100-fold higher levels than that in the normal breast tissues. Expression of the Oct3/4 protein in tumors was confirmed by western blot analysis and immunofluorescent staining. Additionally, rapid amplification of cDNA ends and DNA sequencing revealed expression of multiple Oct4 gene transcripts from chromosome 6 (POU5F1) in normal breast tissues and the non-malignant breast epithelial cell line MCF-10A; by contrast, the breast tumors and malignant breast cancer cell line MCF-7 predominantly expressed transcripts of an Oct4-like gene $(P O U 5 F 1 B)$ from chromosome 8, which was termed Oct 3 in the current study. The deduced amino acid sequences of full-length Oct 3 and Oct 4 are $96 \%$ identical. The findings of the current study indicated that Oct 3 , rather than Oct4, may serve as a novel clinical marker and a potential target for gene-specific therapy of breast cancer.
\end{abstract}

\section{Introduction}

Oct4, also known as Oct3 or POU class 5 homeobox 1 (POU5F1) gene, is a member of the POU transcription factor

Correspondence to: Dr Feng-Qi Zhao, Department of Animal and Veterinary Sciences, University of Vermont, Terrill Building, 570 Main Street, Burlington, VT 05405, USA

E-mail: fzhao@uvm.edu

Key words: breast cancer, gene expression, isoform, Oct3/4, oncogene, transcription factor family, the members of which have a structurally characteristic POU-specific domain (POU-S) and a POU homeodomain (POU-H) that are required for specific and efficient DNA binding $(1,2)$. Oct $3 / 4$ is specifically expressed in totipotent mouse and human embryonic stem (ES) and germ cells $(3,4)$ and is considered to be a gatekeeper during the early steps of mammalian embryogenesis due to its pivotal role in the regulation and maintenance of ES cell pluripotency and self-renewal (4-6). Loss of Oct3/4 alters the fate of inner blastocyst cells in the early mouse embryo to prevent them from becoming the inner cell mass or further differentiating into the trophectoderm lineage (7). Oct $3 / 4$ expression is downregulated when embryonic stem cells are triggered to differentiate and does not occur in normal somatic cells in differentiated tissues $(7,8)$.

There is mounting evidence for an association between Oct $3 / 4$ and carcinogenesis. Increased Oct $3 / 4$ expression (up to $150 \%$ of normal expression) in ES cells promotes the potential of these cells to form tumors in syngeneic hosts, from $4 \%$ to $>80 \%$, whereas inactivation causes regression of a malignant phenotype (9). Furthermore, Oct $3 / 4$ has been defined as a diagnostic marker for human testicular germ cell tumor precursor carcinoma, in situ/intratubular germ cell neoplasia undifferentiated, seminoma and embryonal carcinoma (10). In addition to its expression in germ cell tumors, Oct $3 / 4$ has been detected in several somatic tumors, including brain, bladder, gastric, pancreatic, lung and rectal cancer $(8,10-18)$. A transgenic study demonstrated that in vivo activation of Oct $3 / 4$ in adult mouse somatic tissues inhibits cell differentiation in a manner similar to that observed in embryonic cells, resulting in epithelial tissue dysplastic growth in the small intestine and epidermis coupled with progenitor cell expansion (19); the animals die shortly after Oct $3 / 4$ expression is activated. Furthermore, chimeric mice with somatic tissues composed of a mixture of wild type and Oct3/4-inducible cells develop visible skin tumors 3 weeks after induction of Oct 4 expression; however, these tumors completely disappear when Oct $3 / 4$ induction is withdrawn (19).

Oct3/4 expression has been observed in several malignant human breast cancer cell lines, including MCF-7, SKBr3 and MDA-MB-453 cells, but not in normal human breast tissues and cells $(8,12,20-22)$. In breast cancer cells, Oct $3 / 4$ expression 
is repressed by all-trans-retinoic acid and is associated with decreased cell proliferation (22). Oct3/4 expression in these cells upregulates expression of fibroblast growth factor-4 (22), a gene that stimulates MCF-7 cells to become more tumorigenic and metastatic in ovariectomized and tamoxifen-treated nude mice (23). Furthermore, exogenous overexpression of Oct $3 / 4$ in the $4 \mathrm{~T} 1$ mouse mammary cancer cell line increases its ability to form tumor spheres in vitro as well as its tumorigenic potential in vivo (24).

Notably, computational analysis has revealed six putative Oct $3 / 4$ pseudogenes in the human genome (25) and expression of these pseudogenes has been detected in cancer cells and primary tumors (26). Thus, it is possible that certain previous reports of Oct $3 / 4$ expression in cancer may have been the result of Oct-3/4 pseudogene expression. Additionally, two alternatively spliced Oct $3 / 4$ isoforms, originally named Oct $3 \mathrm{~A}$ and Oct3B, in humans have been cloned (27), though it is not known which isoform(s) is/are expressed in breast cancer cells.

In this study, we compared levels of Oct3/4 expression in 28 primary breast tumors and 9 normal breast tissues. Importantly, we reveal, for the first time, differential expression of Oct $3 / 4$ isoforms between breast tumor and normal breast tissues.

\section{Materials and methods}

Breast tumor and normal breast tissue specimen collection. Breast tumor and normal breast tissue specimens were collected from 28 patients with primary breast cancer following lumpectomy or mastectomy and from 9 women undergoing cosmetic mammoplasties at the Department of Surgery, University of Vermont Medical Center (Burlington, VT, USA) from March 2008 to February 2009. Tumor clinicopathological parameters for each patient were also obtained in a blinded manner. Patient ages were unknown, and all patient tissue samples from which RNA could be isolated were used in this study. The study protocol was approved and the requirement for informed patient consent was waived by the Institutional Review Boards of the University of Vermont (no. M08-186). The tissues were immediately snap-frozen in liquid nitrogen and stored at $-80^{\circ} \mathrm{C}$ until RNA and protein isolation. For histological and immunofluorescence analyses, 1-2 small pieces $\left(\sim 1 \mathrm{~mm}^{3}\right)$ of individual mammary tissues were fixed in freshly prepared $4 \%(\mathrm{w} / \mathrm{v})$ paraformaldehyde (Sigma-Aldrich; Merck KGaA, Darmstadt, Germany) for $4 \mathrm{~h}$ at $4^{\circ} \mathrm{C}$, followed by overnight immersion in $0.5 \mathrm{M}$ sucrose in phosphate-buffered saline (PBS) at $4^{\circ} \mathrm{C}$. The fixed tissues were embedded in an optimum cutting temperature compound (Sakura Finetek USA, Inc., Torrance, CA, USA), frozen in liquid-nitrogen-chilled isopentane and stored at $-80^{\circ} \mathrm{C}$.

F9 cell lysate and culture of MCF-7 and MCF-10A cells. F9 cell lysate was purchased from Santa Cruz Biotechnology, Inc. (Dallas, TX, USA). MCF-7 (cat. no. HTB-2) and MCF-10A (cat. no. CRC-10317) cells were obtained from the American Type Culture Collection (ATCC; Manassas, VA, USA). MCF-7 cells were cultured in Eagle's minimum essential medium (ATCC; cat. no. 30-2003) supplemented with $10 \%$ fetal bovine serum (Invitrogen; Thermo Fisher Scientific, Inc., Waltham,
MA, USA), $0.01 \mathrm{mg} / \mathrm{ml}$ bovine insulin (Sigma-Aldrich; Merck $\mathrm{KGaA}$ ), and $50 \mathrm{mg} / \mathrm{ml}$ gentamycin (Invitrogen; Thermo Fisher Scientific, Inc.). MCF-10A cells were grown in Mammary Epithelial Growth Medium (cat. no. CC-3051; Cambrex Corporation, East Rutherford, NJ, USA) supplemented with $100 \mathrm{ng} / \mathrm{ml}$ cholera toxin (cat. no. 227035; Calbiochem; Merck KGaA).

RNA isolation and purification and reverse transcriptionquantitative polymerase chain reaction ( $R T-q P C R)$. polyA $^{+}$RNA was isolated from MCF-7 and MCF-10A cells using FastTrack ${ }^{\circledR} 2.0$ mRNA Isolation kit (Invitrogen; Thermo Fisher Scientific, Inc.). Total RNA was extracted from tumor and normal breast tissues using the TRIzol ${ }^{\circledR}$ reagent (Thermo Fisher Scientific, Inc.), treated with 0.3 U DNase I at room temperature for $15 \mathrm{~min}$, and column-purified using the Qiagen RNAeasy Mini kit (Qiagen, Inc., Valencia, CA, USA) according to the manufacturer's instructions. Total RNA $(1 \mu \mathrm{g})$ was used to generate cDNA using the GeneAMP kit (Applied Biosystems; Thermo Fisher Scientific, Inc.). RT-qPCR analysis was performed using an ABI PRISM 7900 with TaqMan Assays On Demand Gene Expression kits (Applied Biosystems; Thermo Fisher Scientific, Inc.) specific for human Oct3/4 (cat. no. Hs00999632_g1) and for the housekeeping genes hypoxanthine phosphoribosyltransferase 1 (HPRT1; cat. no. Hs99999909_m1) and GAPDH (cat. no. Hs99999905_m1). Reactions were performed in duplicate in a 20- $\mu 1$ volume containing $10 \mu \mathrm{l}$ Quanta PerfeCTa qPCR SuperMix (Quantabio, Beverly, MA, USA), $1.0 \mu 1$ TaqMan assay and $1 \mu \mathrm{l}$ diluted cDNA (corresponding to $50 \mathrm{ng}$ of reverse-transcribed total RNA). The following PCR conditions were used: Initial denaturation at $95^{\circ} \mathrm{C}$ for $10 \mathrm{~min}$ and 40 cycles of $95^{\circ} \mathrm{C}$ for $15 \mathrm{sec}$ and $60^{\circ} \mathrm{C}$ for $1 \mathrm{~min}$. Relative expression of Oct $3 / 4$ was calculated with the $2^{-\Delta \Delta C \mathrm{CT}}$ method (28) and normalized against HPRT and GAPDH.

Rapid amplification of cDNA ends (RACE) of human Oct 3/4 isoforms and cloning of full-length Oct3/4 transcript variant $c D N A s$. The 3 ' and 5' sequences of human Oct3/4 were obtained by RACE using SMART RACE cDNA Amplification kit (Clontech Laboratories, Inc., Mountainview, CA, USA). 3'- and 5'-RACE-ready first-strand cDNAs were synthesized using polyA $^{+}$RNA from MCF-7 or MCF-10A cells or total RNA pooled from all 28 breast cancer tissues or all 9 normal breast tissues. The Oct3/4 5' sequences were first amplified using the provided universal primer (UPR; Clontech Laboratories, Inc.) and an Oct3/4-specific reverse primer (159R; Table I) and then reamplified using the provided nested universal primer (NUP; Clontech Laboratories, Inc.) and a nested Oct3/4-specific reverse primer (155R for cells or $161 \mathrm{R}$ for tissues; Table I). Similarly, the 3 ' sequence of Oct3/4 was first amplified using UPM and an Oct3/4-specific forward primer (154F; Table I) and reamplified using NUP and a nested Oct3/4-specific forward primer (158F for cells or $160 \mathrm{~F}$ for tissues; Table I). The resulting PCR products were gel-purified, cloned into the $\mathrm{pCR}^{\circledR} 2.1$ vector (Clontech Laboratories, Inc.), and sequenced by the Vermont Cancer Center DNA Core Facility using an ABI 3730 (Applied Biosystems; Thermo Fisher Scientific, Inc.). The RACE product sequences were verified in at least three independent clones. 
Table I. Sequences of oligonucleotide primers used for PCR and rapid amplification of 5' and 3 ' cDNA ends.

\begin{tabular}{lc}
\hline Primer name & Sequence \\
\hline $154 \mathrm{~F}$ & 5'-CCAAGCTCCTGAAGCAGAAG-3' \\
$155 \mathrm{R}$ & 5'-GCCGGTTACAGAACCACACT-3' \\
$158 \mathrm{~F}$ & 5'-GGCTCTGCAGCTTAGCTTCA-3' \\
$159 \mathrm{R}$ & 5'-CCGAGGAGTACAGTGCAGTG-3' \\
$160 \mathrm{~F}$ & 5'-CACTTCACTGCACTGTACTC-3' \\
$161 \mathrm{R}$ & 5'-CACATCGGCCTGTGTATATC-3' \\
$164 \mathrm{R}$ & 5'-TTACTGTGTCCCAGGCTTCT-3' \\
$165 \mathrm{R}$ & 5-TTCACCTTCCCTCCAACCAG-3' \\
$166 \mathrm{~F}$ & 5'-GATCCAAGTGGGCAACTTGA-3' \\
$168 \mathrm{~F}$ & 5'-CTGAGACATGATGCTCTTCC-3' \\
$170 \mathrm{~F}$ & 5'-TGATGCTTCAGGCACTGTGT-3' \\
$172 \mathrm{~F}$ & 5'-AATCTGGACCTGAGCGAGAA-3' \\
\hline
\end{tabular}

F, forward; R, reverse.

Full-length Oct3/4 transcript variant cDNAs were first PCR-amplified from the 5'-RACE-ready first-strand cDNAs from either MCF-7 or MCF-10A cells using Advantage 2 polymerase (Clontech Laboratories, Inc.) with the UPM-A primer (Clontech Laboratories, Inc.) and a gene-specific primer (164R or $165 \mathrm{R}$, Table I); the sequences were reamplified with $165 \mathrm{R}$ and the following specific forward primer for each individual transcript: i) 170F (Oct3; GenBank accession no. DQ486513.1); ii) $166 \mathrm{~F}$ (Oct4; GenBank accession no. DQ486514.1); iii) $168 \mathrm{~F}$ (GenBank accession nos. DQ486515.1 and DQ486516.1); and iv) 172F (GenBank accession no. DQ486517.1; Table I). The primers were designed to correspond with the far $5^{\prime}$ or 3' region of each individual transcript. The PCR products were gel-purified and cloned into the pCR 2.1 vector. Each full-length cDNA was sequenced, verified in at least three independent clones, and submitted to GenBank under accession nos. DQ486513.1-DQ486517.1.

DNA sequence analysis. cDNA sequence analysis was conducted using Lasergene (version 3; DNASTAR, Inc., Madison, WI, USA) computer program and the National Center for Biotechnology Information (blast.ncbi.nlm.nih.gov/Blast.cgi) BLAST site. Multiple sequence alignment was performed using the European Molecular Biology Laboratory MAFFT site (ebi.ac.uk/Tools/ $\mathrm{msa} / \mathrm{mafft}$ ) and viewed with the GeneDoc program (psc.edu/ biomed/genedoc).

In vitro transcription and translation. Full-length Oct $3 / 4$ transcript cDNAs were transcribed in vitro by $\mathrm{T} 7$ polymerase and translated in the presence of L-[35S]methionine (GE Healthcare, Chicago, IL, USA) using the TNT $^{\circledR}$ Coupled Reticulocyte Lysate System (Promega Corporation, Madison, WI, USA) according to the manufacturer's instructions. The translation products were resolved by $12 \%$ (w/v) SDS-PAGE and the radioimaging was captured by a phosphor-capture screen and analyzed using Quantity One software (version 4.2.1) with a Molecular Imager FX (Bio-Rad Laboratories, Inc., Hercules, CA, USA).
Western blot analysis. Whole-tissue and cell lysates $(25 \mu \mathrm{g}$ total protein) extracted using T-PER ${ }^{\mathrm{TM}}$ Tissue Protein Extraction Reagent (Thermo Fisher Scientific, Inc.) were resolved by $12 \%$ (w/v) SDS-PAGE using Mini-PROTEAN III Cell system (Bio-Rad Laboratories, Inc.). Proteins were electrophoretically transferred at $4^{\circ} \mathrm{C}$ to a polyvinylidene fluoride membrane (GE Healthcare). The blot was blocked for $1 \mathrm{~h}$ at room temperature in Tris-buffered saline (TBS; $50 \mathrm{mM}$ Tris-Cl, pH 7.5 and $150 \mathrm{mM} \mathrm{NaCl}$ ) with $0.1 \%$ Tween-20 (TBS-T) containing 5\% non-fat dry milk (w/v) and incubated overnight at $4^{\circ} \mathrm{C}$ in TBS-T containing 5\% non-fat dry milk and $1 \mu \mathrm{g} / \mathrm{ml}$ anti-Oct3/4 antibody (cat. no. ab19857; Abcam, Cambridge, MA, USA) or $1 \mu \mathrm{g} / \mathrm{ml}$ anti-Oct $3 / 4$ antibody that had been pre-incubated with a 5-fold excess (molar concentration) of blocking polypeptide (cat. no. ab20650; Abcam) for $1 \mathrm{~h}$ at room temperature. The membrane was washed twice at room temperature for $20 \mathrm{~min}$ with TBS-T and incubated for $1 \mathrm{~h}$ at room temperature in TBS-T with $2 \%$ non-fat dried milk and a 1:5,000 dilution of a goat anti-rabbit secondary antibody conjugated with horseradish peroxidase (cat. no. NA9340; GE Healthcare). Detection of the protein-primary antibodysecondary antibody immune complex was performed using the SuperSignal West Pico Chemiluminescent substrate (Pierce; Thermo Fisher Scientific, Inc.).

Immunofluorescence staining. For Oct3/4 immunohistochemical staining, embedded tissues were sectioned $(10 \mu \mathrm{m})$, thaw-mounted onto the surface of gelatin-coated slides, and incubated in 10\% normal goat serum (Thermo Fisher Scientific, Inc.) at room temperature for $30 \mathrm{~min}$ to block non-specific antibody binding. The sections were then incubated with either diluted anti-Oct-3/4 (cat. no. ab19857; Abcam; $2 \mu \mathrm{g} / \mathrm{ml}$ ) in PBS with $1 \%$ bovine serum albumin (BSA) or normal rabbit $\mathrm{IgG}$ for $1 \mathrm{~h}$ at $37^{\circ} \mathrm{C}$. For an additional control, some sections were incubated with an anti-Oct $3 / 4$ antibody that had been pre-incubated with a 5-fold excess (molar concentration) of blocking polypeptide (cat. no. ab20650; Abcam) for $1 \mathrm{~h}$ at room temperature. After being washed twice in PBS with $1 \%$ BSA for $5 \mathrm{~min}$, the sections were incubated for $1 \mathrm{~h}$ at room temperature in the dark with a 1:4,000 dilution of secondary antibody conjugated with Alexa Fluor 647 (cat. no. A-21244; Molecular Probes; Thermo Fisher Scientific, Inc.). After three washes in PBS with $1 \%$ BSA for $5 \mathrm{~min}$, the sections were stained with the nuclear stain DAPI (Molecular Probes; Thermo Fisher Scientific, Inc.) diluted 1:10,000 in PBS for $5 \mathrm{~min}$ at room temperature. Finally, the sections were washed twice in PBS with $1 \%$ BSA for $15 \mathrm{~min}$, once in PBS, and once in distilled water before being mounted onto glass microscope slides using Aqua-Poly/Mount (Polysciences, Inc., Warrington, PA, USA). The sections were then examined under a confocal microscope (LSM 510; Zeiss AG, Thornwood, NY, USA).

Statistical analysis. Data are presented as the mean \pm standard error. Statistical analysis of mRNA expression was performed using the JMP software package (SAS Institute, Inc., Cary, NC, USA). Differences in the means of Oct3/4 mRNA expression between breast cancer and normal breast tissues were compared using Student's t-test. Logistic regression of Oct3/4 mRNA expression and tumor types was analyzed using the 
Table II. Oct3/4 mRNA expression in 28 primary breast tumor tissues.

\begin{tabular}{|c|c|c|c|c|c|c|c|c|c|c|}
\hline \multirow[b]{2}{*}{$\begin{array}{l}\text { Patient } \\
\text { no. }\end{array}$} & \multirow[b]{2}{*}{ Tumor histology } & \multirow{2}{*}{$\begin{array}{c}\text { Level of } \\
\text { differentiation }\end{array}$} & \multirow{2}{*}{$\begin{array}{l}\text { Tumor } \\
\text { size }^{\mathrm{a}}\end{array}$} & \multirow{2}{*}{$\begin{array}{l}\text { Lymph node } \\
\text { spread }^{\mathrm{a}}\end{array}$} & \multirow[b]{2}{*}{ Metastasis $^{\mathrm{a}}$} & \multicolumn{3}{|c|}{ Receptor status } & \multicolumn{2}{|c|}{ Oct $3 / 4$ mRNA $^{\mathrm{d}}$} \\
\hline & & & & & & $\overline{E^{b}}$ & $\mathrm{PR}^{\mathrm{b}}$ & Her $2^{c}$ & GAPDH & HPRT1 \\
\hline 01 & IDCA & Poor & $\mathrm{T} 2$ & NO & $\mathrm{Mx}$ & 0 & 0 & 0 & 92.31 & 172.42 \\
\hline 04 & IDCA & Poor & $\mathrm{T} 1 \mathrm{c}$ & No & $+\mathrm{M}$ & 0 & 0 & 0 & 74.96 & 121.76 \\
\hline 05 & IDCA & Moderate & $\mathrm{T} 1 \mathrm{c}$ & N0 & $\mathrm{Mx}$ & 90 & 90 & $2 \mathrm{NA}$ & 170.26 & 228.6 \\
\hline 07 & IDCA & Well & $\mathrm{T} 1 \mathrm{c}$ & No & $\mathrm{Mx}$ & 90 & 90 & 0 & 214.66 & 139.69 \\
\hline 08 & IDCA & Moderate & $\mathrm{T} 1 \mathrm{c}$ & No & Mx & 0 & 0 & 1 & 71.5 & 92.76 \\
\hline 10 & $\begin{array}{l}\text { Fibroepthelial } \\
\text { fibroadenoma } \\
\text { and phyllodes }\end{array}$ & & & & & & & & 311.56 & 339.49 \\
\hline 11 & IDCA & Poor & $\mathrm{T} 1 \mathrm{c}$ & N3 & $\mathrm{Mx}$ & $>90$ & $<5$ & 0 & 305.95 & 149.96 \\
\hline 12 & IDCA & Poor & $\mathrm{T} 2$ & No & $\mathrm{Mx}$ & 80 & 90 & 0 & 160.2 & 148.65 \\
\hline 14 & Lobular and IDCA & Moderate & $\mathrm{T} 2$ & $\mathrm{~N} 1$ & $\mathrm{Mx}$ & $>90$ & $>90$ & 0 & 98.87 & 63.84 \\
\hline 15 & IDCA & Poor & $\mathrm{T} 2$ & No & $\mathrm{Mx}$ & 70 & 90 & $2 \mathrm{~A}$ & 157.96 & 228.54 \\
\hline 16 & IDCA & Poor & $\mathrm{T} 2$ & N3 & $\mathrm{Mx}$ & $>90$ & 0 & 0 & 116.73 & 153.52 \\
\hline 17 & IDCA & Moderate & T1c & NO & Mx & 90 & 80 & 1 & 129.51 & 225.54 \\
\hline 18 & IDCA & Poor & $\mathrm{T} 1 \mathrm{c}$ & No & $\mathrm{Mx}$ & 0 & 60 & 3 & 34.59 & 101.30 \\
\hline 19 & IDCA & Moderate & $\mathrm{T} 1 \mathrm{c}$ & NO & $\mathrm{Mx}$ & 90 & $>90$ & 0 & 330.59 & 208.13 \\
\hline 21 & IDCA & Poor & $\mathrm{T} 2$ & No & $\mathrm{Mx}$ & 0 & 0 & 0 & 746.42 & 485.89 \\
\hline 23 & IDCA & Poor & $\mathrm{T} 2$ & N1 & $\mathrm{Mx}$ & 90 & 0 & 0 & 170.83 & 171.86 \\
\hline 24 & IDCA & Moderate & $\mathrm{T} 1 \mathrm{c}$ & No & $\mathrm{Mx}$ & 90 & 30 & 1 & 149.59 & 82.77 \\
\hline 25 & IDCA & Moderate & $\mathrm{T} 2$ & NO & $\mathrm{Mx}$ & 90 & $>90$ & 0 & 176.65 & 284.85 \\
\hline 27 & IDCA & Poor & $\mathrm{T} 2$ & No & $\mathrm{Mx}$ & 0 & 0 & 2 & 230.54 & 229.01 \\
\hline 28 & IDCA & Mild & $\mathrm{T} 2$ & $\mathrm{~N}$ & Mx & $>90$ & $>90$ & 0 & 136.86 & 191.85 \\
\hline 30 & IDCA & Moderate & $\mathrm{T} 3$ & $\mathrm{~N}$ & $\mathrm{Mx}$ & 90 & 0 & 0 & 128.65 & 125.84 \\
\hline 31 & IDCA & Moderate & $\mathrm{T} 2$ & No & Mx & $>90$ & 0 & 0 & 265.90 & 237.90 \\
\hline 34 & IDCA & Moderate & $\mathrm{T} 1 \mathrm{~b}$ & No & $\mathrm{Mx}$ & $>90$ & 80 & 0 & 360.97 & 240.54 \\
\hline 35 & IDCA & Poor & $\mathrm{T} 2$ & $\mathrm{~N} 1$ & $\mathrm{Mx}$ & 80 & 90 & 1 & 162.73 & 222.87 \\
\hline 36 & IDCA & Lobular features & $\mathrm{T} 2$ & No & Mx & $>90$ & 60 & 2 & 157.54 & 129.37 \\
\hline 37 & $\begin{array}{l}\text { IDCA and focal } \\
\text { medullary features }\end{array}$ & Poor & $\mathrm{T} 1 \mathrm{c}$ & No & $\mathrm{Mx}$ & 0 & 0 & 2 & 188.84 & 236.58 \\
\hline 41 & $\begin{array}{l}\text { IDCA and medullary } \\
\text { features }\end{array}$ & Poor & $\mathrm{T} 2$ & N0 & $\mathrm{Mx}$ & 0 & 0 & 0 & 231.80 & 273.61 \\
\hline 42 & IDCA & Poor & $\mathrm{T} 2$ & No & $\mathrm{Mx}$ & & & & 173.42 & 152.30 \\
\hline
\end{tabular}

${ }^{a}$ The TNM Classification of Malignant Tumors: T, tumor size; N0, no lymph node involvement; N1, regional; N2, spread between N1 and N3; $\mathrm{N} 3$, distant and numerous lymph node involvement; Mo/x, no distant metastasis; M1, metastasis to distant organs; ${ }^{b}$ percent positive nuclei (positive, >5\%); ${ }^{\mathrm{C} H e r} 2$ status: A, amplified; NA, non-amplified; 0 or 1, negative; $2 \mathrm{NA}$, negative; $2 \mathrm{~A}$, positive; 3 , positive; ${ }^{\mathrm{d}}$ fold change relative to the mean of normal tissues $(\mathrm{n}=9)$, normalized to the expression levels of either GAPDH or HPRT1. Oct3/4, POU class 5 homeobox 1; IDCA, invasive ductal adenocarcinoma; HPRT1, hypoxanthine phosphoribosyltransferase 1; ER, estrogen receptor; PR, progesterone receptor; Her2, receptor tyrosine-protein kinase erbB-2.

logistic regression package in the $\mathrm{R}$ language program. $\mathrm{P}<0.05$ was considered to indicate a statistically significant difference.

\section{Results}

Strong Oct3/4 expression in primary breast cancer tissues. Oct3/4 expression was previously detected in several malignant human breast cancer cell lines $(12,22)$. To examine Oct3/4 expression in primary breast carcinomas, 28 primary breast tumor tissues were obtained from patients following lumpectomy or mastectomy and 9 normal breast tissues from women undergoing cosmetic surgery. RT-qPCR analysis revealed that, compared with normal breast tissues, all tumor tissues, irrespective of type or clinicopathological status (fibroadenoma, ductal in situ carcinoma, differentiation level, TNM classification, or estrogen, progesterone and receptor tyrosine-protein kinase erbB-2 (Her2) receptor status), strongly expressed Oct3/4 (Table II). Specifically, Oct3/4 mRNA levels were 
A

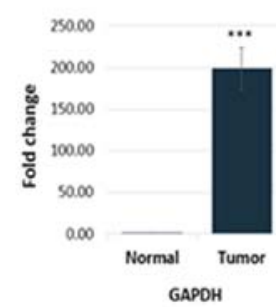

C
B

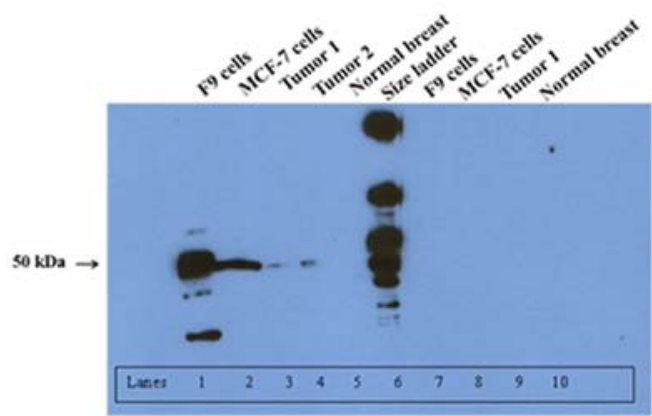

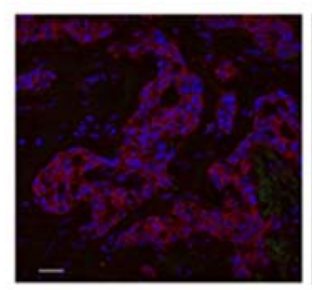
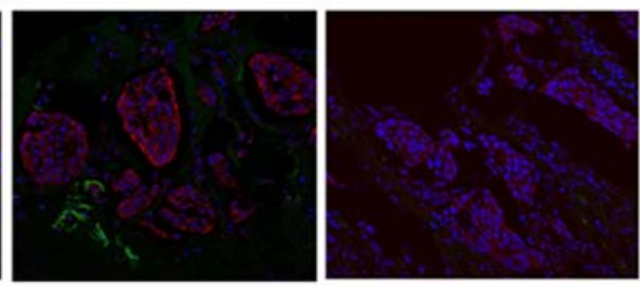

Tumor
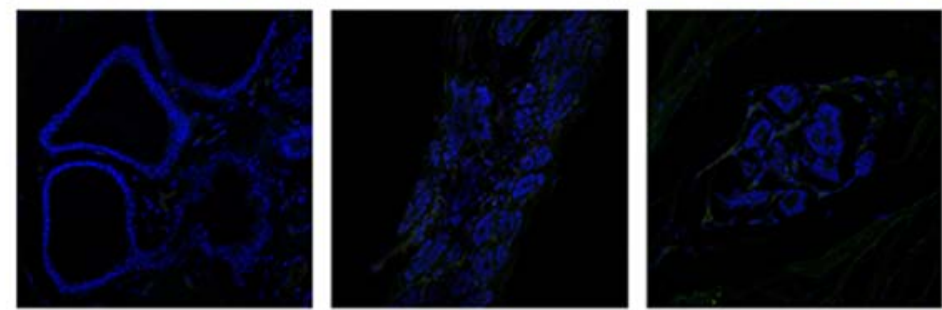

Normal

breast tissue

Figure 1. Oct3/4 expression in primary human breast cancer and normal breast tissues. (A) Oct3/4 mRNA expression levels in 28 breast tumor and 9 normal breast tissues by real-time reverse transcription quantitative-polymerase chain reaction. Relative expression levels of Oct3/4 are normalized by the average expression levels of either GAPDH (left panel) or HPRT1 (right panel). Average expression of Oct $3 / 4$ in normal tissues was set to 1 . ${ }^{* * *} \mathrm{P}<0.001$ vs. normal. (B) Western blot analysis of Oct3/4 protein expression. The amount of the protein loaded in each well was $25 \mathrm{ng}$. Lanes in the blot were loaded as follows: 1 and 7, F9 whole cell lysate as a positive control; 2 and 8, MCF-7 whole cell lysate; 3 and 9, breast tumor sample 1 lysate; 4, breast tumor sample 2 lysate; and 5 and 10, normal mammary gland tissue lysate. The samples in lanes 7-10 were blocked with the Oct3/4 control peptide. (C) Immunofluorescence staining of Oct3/4 (red color). Blue is DAPI nuclear staining, and green is tissue autofluorescence. The upper panels are the staining of breast tumors from 3 patients, and the bottom panels are the staining of 3 normal breast tissues (scale bar, $100 \mu \mathrm{m}$; same magnification). HPRT1, hypoxanthine phosphoribosyltransferase 1

193-fold higher in tumors than in normal breast tissues $(\mathrm{P}<0.001$; Fig. 1A), ranging from 35 - to 746 -fold based on normalization to the expression level of either $G A P D H$ or HPRT1 (Table II). However, logistic regression analysis did not reveal any significant association between Oct $3 / 4$ expression level and tumor phenotype (data not shown).

To examine Oct3/4 protein expression in tumor tissues, western blot analysis was performed. As shown in Fig. 1B, Oct $3 / 4$ protein was detected in two primary breast tumors examined, MCF-7 breast cancer cells, and the positive control F9 cells, but not in normal breast tissues. Preincubation of the anti-Oct3/4 antibody with a control peptide essentially blocked recognition, supporting the specificity of the antibody.

Immunofluorescence staining of Oct $3 / 4$ was performed to further examine and determine the localization of Oct3/4 expression in breast tumors and normal tissues. Strong Oct3/4 staining was observed in all tumors examined, whereas no staining was observed in normal breast tissues (Fig. 1C; staining of three tumors and three normal tissues). The strong staining of Oct3/4 in tumors appeared to mainly occur in cancer cells and not in the stromal tissues surrounding cancer cells within ducts. Essentially, no staining was observed in the tumor and normal tissue sections incubated with either normal rabbit IgG or antiOct $3 / 4$ preincubated with the control peptide (data not shown).
Expression of different Oct3/4 transcripts in breast tumor and normal breast tissues. Multiple Oct3/4 isoforms have been cloned (27), and six pseudogenes highly homologous to Oct3/4 have been previously reported (25). To verify expression of the functional Oct $3 / 4$ gene and identify Oct $3 / 4$ mRNA isoforms in breast cancer cells and tumors, 5'- and 3'-RACE was performed using polyA ${ }^{+}$RNA isolated from MCF-7 breast cancer cells and MCF-10A non-tumorigenic breast epithelial cells (Fig. 2). In 3'-RACE, major, similar-sized products were obtained from both cells (band 10). Cloning and sequencing of band 10 confirmed that it contained the $3^{\prime}$ sequences of Oct 3/4 [the last two exons are the same in all Oct4 transcript variants (POU5F1 on chromosome 6) and $98 \%$ identical to the 3' mRNA sequence of Oct3 (POU5F1B on chromosome 8), Fig. 3 and see below]. However, 5'-RACE produced different products from the two cell lines (Fig. 2). Cloning and sequencing of the 5'-RACE products from MCF-10A cells showed that bands $1,2,3$, and 9 were various Oct4 gene transcripts with different transcription start sites at positions 31167170, 31166838, 31166211 and 31166081, respectively, on chromosome 6 (GRCh38.p7 primary assembly sequence ID: NC_000006.12) and/or exhibited different RNA splicing (Fig. 3). By contrast, the major 5'-RACE products from MCF-7 cells (bands 4-6) consisted of various Oct3 transcripts 


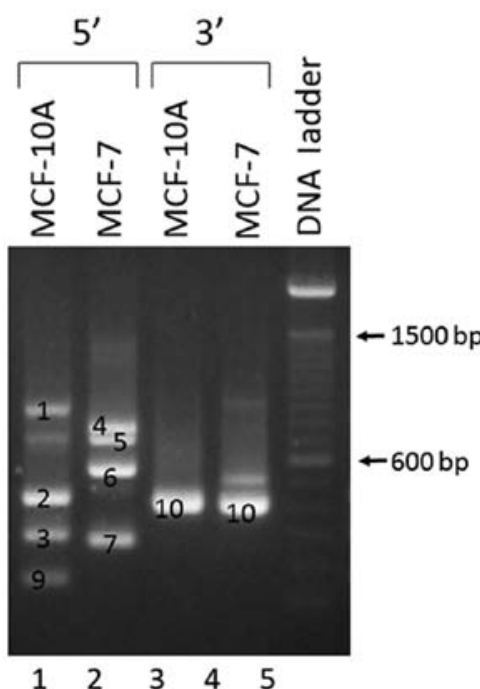

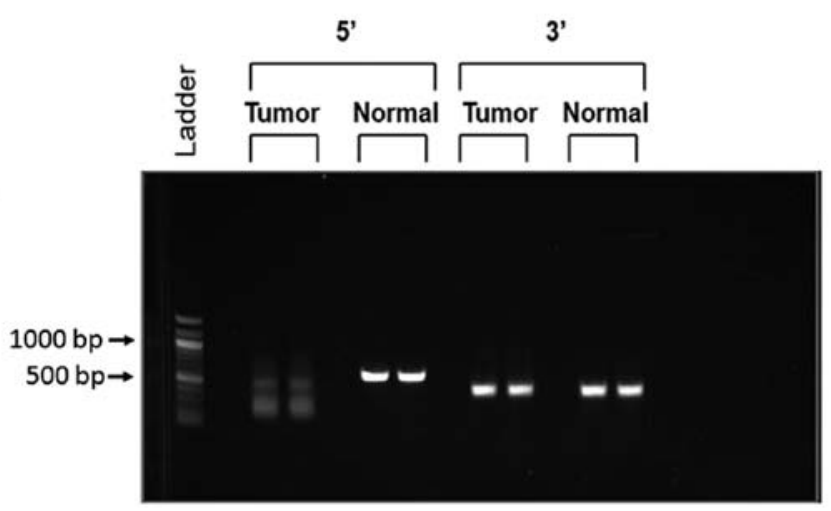

Figure 2. (A) RACE of human Oct 3/4 transcripts in MCF-7 and MCF-10A cells. The bands are numerically labeled. (B) RACE of human Oct 3/4 transcripts in primary breast cancer and normal breast tissues. Each RACE product was loaded in two lanes (for gel purification purposes). RACE, rapid amplification of 5'- and 3'-cDNA ends. The DNA ladder used in (A) and (B) was the 100 bp DNA Ladder from Thermo Fisher Scientific, Inc. and New England Biolabs, Inc., respectively.

A

Oct4: NC_000006.12: 31.M....31M (8.3Kbp)

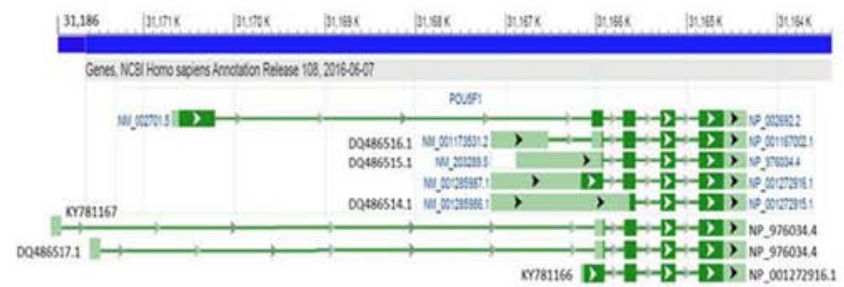

Oct3: NC 000008.11: 127M...127M (2.1Kbp)

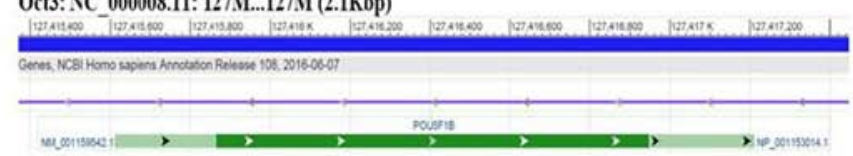

B

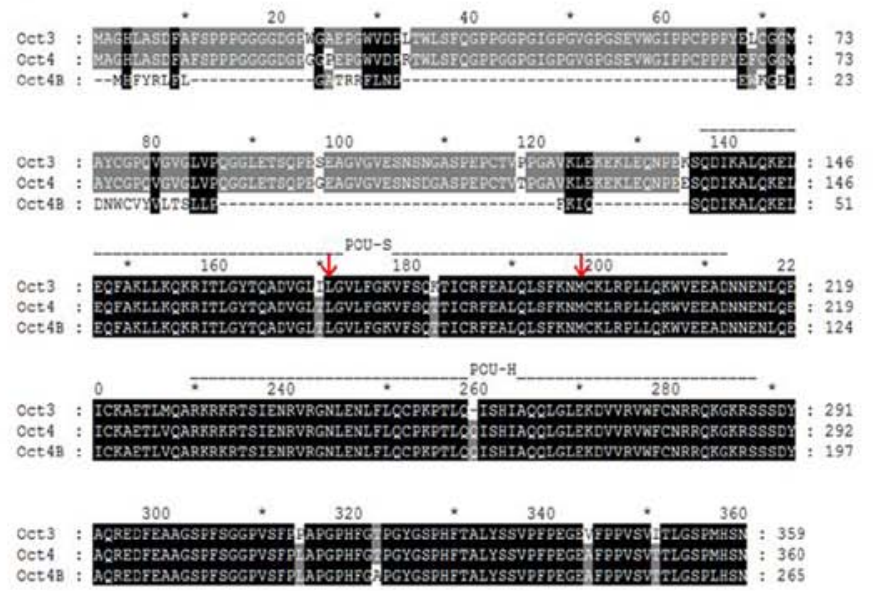

Figure 3. Oct3/4 isoforms. (A) Genomic organization of Oct4 (upper panel) and Oct3 genes (bottom panel). GenBank accession numbers for the different sequences obtained in this study and the sequences obtained from GenBank are indicated. This figure is adapted and modified from the National Center for Biotechnology Information website. Filled boxes represent translated regions and empty boxes untranslated regions. The potential use of a downstream AUG or non-AUG start codon to produce the 160- or 190-aa product is based on Wang et al (32). (B) Amino acid sequence alignment of Oct3 and Oct4 and 4B isoforms. The GenBank protein identification numbers of these sequences are NP_001153014.1 (Oct3), NP_002692.2 (Oct4), and NP_001272916.1 (Oct4B). The alignment was performed with the MAFFT program. Residues highlighted with black shading represent conserved amino acids; gray shading indicates two conserved residues at that position. Positions of the POU-S and the POU-H are given by dashed lines on top of the sequence alignment. Evidence has shown that a 190-amino acid isoform can result from translation at a downstream in-frame CUG codon (arrow pointed ' $L$ ') and that a 164-amino acid isoform can result from usage of a downstream AUG codon (arrow pointed 'M') (32). kbp, kilo base; POU-S, POU-specific domain; POU-H, POU homeodomain.

(intronless) starting at different positions on chromosome 8, and band 7 was revealed to be another Oct4 transcript that starts at position 31180731 on chromosome 6 (Fig. 3). Thus, the RACE results indicated that MCF-10A and MCF-7 cells express different Oct4 (POU5F1) and Oct3 (POU5F1B) gene transcripts from different chromosomes.

To examine the Oct $3 / 4$ transcripts expressed in breast tumor and normal breast tissues, RACE was performed using total RNA pooled from all 28 breast tumors or all 9 normal breast tissues. As shown in Fig. 2 and consistent with the
RACE results obtained using MCF-7 and MCF-10A cells, one similar-sized band was obtained from tumor and normal tissues by 3 -RACE, whereas 5'-RACE resulted in different bands from tumor and normal tissues (one single bright band from normal tissues vs. weak, smaller and diffused bands from tumor tissues). Verification by cloning and sequencing revealed that the 3'-RACE products from tumor tissues comprised both Oct 3 and Oct 4 transcripts and a transcript from chromosome 1 (an Oct4 pseudogene), and the 3' products from normal tissues contained the Oct 4 transcript and the same transcript 
Table III. Putative human Oct3/4 isoforms.

\begin{tabular}{|c|c|c|c|c|c|c|c|}
\hline \multirow[b]{2}{*}{ Name $^{a}$} & \multicolumn{4}{|c|}{ Gene } & \multicolumn{3}{|c|}{ Protein } \\
\hline & Symbol & Chromosome & $\begin{array}{l}\text { Transcripts (GenBank } \\
\text { accession no.) }\end{array}$ & Exons & $\begin{array}{c}\text { GenBan } \\
\text { accession no. }\end{array}$ & $\begin{array}{l}\text { Amino acid } \\
\text { length }\end{array}$ & $\begin{array}{l}\text { Size } \\
(\mathrm{Da})\end{array}$ \\
\hline $\operatorname{Oct} 4(\mathrm{~A})$ & $\begin{array}{l}\text { POU5F1 } \\
\text { (NCBI ID 5460) }\end{array}$ & $6(6 \mathrm{p} 21.33)^{\mathrm{c}}$ & $\begin{array}{l}\text { Variant 1 }{ }^{\mathrm{e}}(\mathrm{NM} \text { _002701.5, } \\
\text { Z11898.1) }\end{array}$ & 5 & NP_002692.2 & 360 & 38,571 \\
\hline Oct $4 B$ & POU5F1 & $6(6 \mathrm{p} 21.33)^{\mathrm{c}}$ & $\begin{array}{l}\text { Variant 5 } 5^{\mathrm{e}} \text { (NM_001285987.1, } \\
\text { Z11899.1), KY781166 }\end{array}$ & 4 & NP_001272916.1 & 265 & 29,954 \\
\hline Oct $4-190^{b}$ & POU5F1 & $6(6 \mathrm{p} 21.33)^{\mathrm{c}}$ & 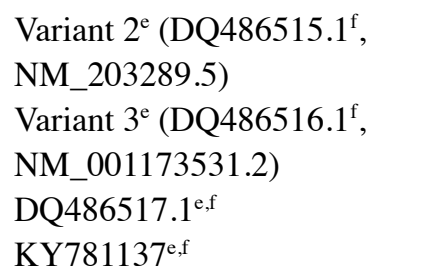 & $\begin{array}{l}4 \\
5 \\
5 \\
5 \\
5\end{array}$ & $\begin{array}{l}\text { NP_976034.4, } \\
\text { NP_001167002.1 }\end{array}$ & 190 & 21,127 \\
\hline Oct4-164 & POU5F1 & $6(6 \mathrm{p} 21.33)^{\mathrm{c}}$ & $\begin{array}{l}\text { Variant } 4 \text { (DQ486514.1 }{ }^{\mathrm{f}} \text {, } \\
\text { NM_001285986.1) }\end{array}$ & 3 & NP_001272915 & 164 & 18,310 \\
\hline Oct3 & $\begin{array}{l}\text { POU5F1B } \\
(\text { NCBI ID 5462) }\end{array}$ & $8(8 Q 24.21)^{\mathrm{d}}$ & $\begin{array}{l}\text { DQ486513.1 }{ }^{\mathrm{f}} \text {, } \\
\text { NM_001159542.1,Z11901.1 }\end{array}$ & Intronless & NP_001153014.1 & 359 & 38,457 \\
\hline
\end{tabular}

${ }^{a}$ Proposed names for different putative Oct $3 / 4$ isoforms. ${ }^{b}$ Isoform results from translation at an in-frame non-AUG (CUG) start codon (32). ${ }^{\mathrm{c} G e}$ nomic sequence: GenBank accession no. NC_000003.12, GRCh38.p7 assembly. ${ }^{\mathrm{d}}$ Genomic sequence: GenBank accession no. NC_000008.11, GRCh38.p7 assembly. ${ }^{\mathrm{e}}$ Transcripts may encode shorter isoforms through the use of alternative downstream AUG or non-AUG start codons (32). ${ }^{\mathrm{f} S e q u e n c e s}$ obtained in the current study. POU5F1/Oct4, POU class 5 homeobox 1; POU5F1B/Oct3, POU class 5 homeobox 1B.

from chromosome 1 . The 5'-RACE products from tumor and normal tissues were all Oct4 transcripts. However, the transcription start sites of the Oct4 transcripts from breast tumors were between $31,186,202$ and 31,186,092 on chromosome 6, whereas the start site of the Oct4 transcript from normal breast tissues was at 31,166,274 on chromosome 6 (Fig. 3).

Cloning and in vitro transcription and translation of Oct3/4 transcript variants, genomic organization and sequence alignment of Oct3/4 isoforms. The full-length cDNAs of various Oct3/4 transcripts were amplified from the MCF-7 or MCF-10A cell 5'-RACE libraries. For the Oct3 transcript (the longest sequence corresponds to bands 4-6 in Fig. 2) and each Oct4 transcript (corresponding to bands 1-3, 7 and 9), the first PCR reactions were performed using the UPM-A primer and a reverse Oct3/4-specific primer close to the polyA ${ }^{+}$site; the second PCR was performed using a nested forward primer at the farthest possible 5' site in each individual transcript with either the same reverse primer used in the first PCR or a nested reverse primer very close to the first reverse primer. Using this approach, the full-length cDNAs of Oct3 (DQ486513) and several Oct4 transcripts were successfully amplified, including DQ486514 (corresponding to the band 1 transcript, that also included bands 3 and 9), DQ486515 (transcript A of band 2), DQ489516 (transcript B of band 2), and DQ486517 (band 7; Fig. 3 and Table III); these cDNA sequences were submitted to GenBank under accession nos. DQ486513.1-DQ486517.1, respectively. Sequence analysis of these transcripts indicated that the Oct 3 transcript contains an open reading frame (ORF) that encodes the full-length Oct3 protein; conversely, none

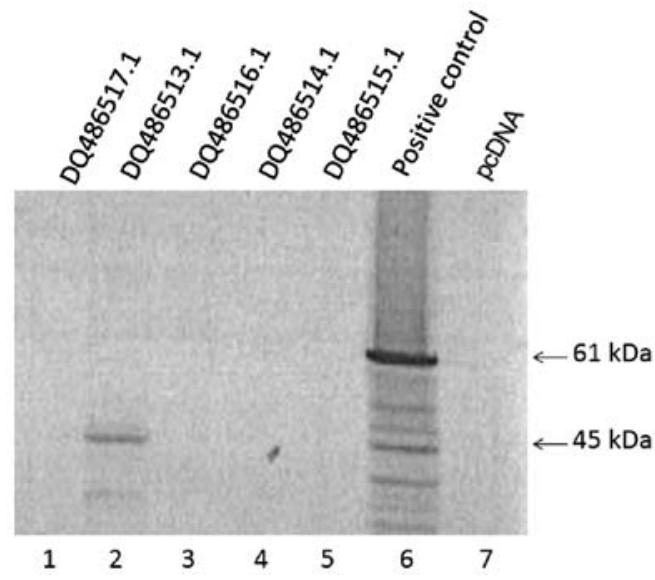

Figure 4. In vitro transcription and translation products of full-length Oct $3 / 4$ cDNAs cloned in this study (GenBank nos. DQ486513.1-DQ486517.1). The positive control was supplied by the Promega TNT ${ }^{\circledR}$ Coupled Reticulocyte Lysate System kit. The positions of the two protein size markers are indicated.

of the Oct4 transcripts harbor an ORF that encodes an Oct4 isoform with intact POU-S and POU-H domains.

Subsequently, coupled in vitro transcription and translation was performed to characterize the different Oct3/4 full-length cDNA sequences obtained (Fig. 4). Consistent with sequence analysis, only DQ486513 (Oct3 transcript), but none of the Oct4 transcripts, produced translation products.

Furthermore, two new Oct4 transcripts were predicted based on our 5'- and 3'-RACE results from normal breast and breast tumor tissues (KY781166 and KY781167; Fig. 3). 
Table IV. Oct3 mRNA homology to sequences in the human genome. ${ }^{\text {a }}$

\begin{tabular}{|c|c|c|c|c|c|c|}
\hline $\begin{array}{l}\text { Corresponding } \\
\text { gene }\end{array}$ & $\begin{array}{l}\text { Chromosome } \\
\text { location }\end{array}$ & $\begin{array}{l}\text { NCBI reference } \\
\text { sequence } \\
\text { (accession no.) }\end{array}$ & $\begin{array}{l}\text { Region of } \\
\text { Oct } 3 \text { cDNA }\end{array}$ & Sequence range & $\begin{array}{l}\text { Length } \\
\text { (bp) }\end{array}$ & $\begin{array}{c}\text { Homology } \\
(\%)\end{array}$ \\
\hline POU5F1P4 & $1 \mathrm{q} 22$ & NC_000001.11 & $216-1,561$ & $155,433,140-155,434,489$ & 1,349 & 96 \\
\hline POU5F1P6 & $3 q 21.3$ & NC_000003.12 & $\begin{array}{l}211-780 \\
768-949 \\
1,048-1,583\end{array}$ & $\begin{array}{l}128,677,051-128,676,528 \\
128,675,568-128,675,388 \\
128,674,928-128,674,421\end{array}$ & $\begin{array}{l}523 \\
180 \\
507\end{array}$ & $\begin{array}{l}80 \\
92 \\
86\end{array}$ \\
\hline POU5F1 (Oct4) & $6 \mathrm{p} 21.33$ & NC_000006.12 & $\begin{array}{l}214-660 \\
659-782 \\
781-915 \\
911-1,071 \\
1,069-1,583\end{array}$ & $\begin{array}{l}31,170,662-31,170,216 \\
31,166,049-31,165,929 \\
31,165,702-31,165,568 \\
31,165,288-31,165,125 \\
31,164,867-31,164,352\end{array}$ & $\begin{array}{l}446 \\
120 \\
134 \\
163 \\
515\end{array}$ & $\begin{array}{l}97 \\
99 \\
98 \\
98 \\
98\end{array}$ \\
\hline POU5F1B (Oct3) & $8 \mathrm{q} 24.21$ & NC_000008.11 & $1-1,583$ & $127,415,612-127,417,194$ & 1,582 & 100 \\
\hline POU5F1P2 & $8 \mathrm{q} 22.3$ & & $516-1,579$ & $102,621,247-102,622,271$ & 1,024 & 80 \\
\hline POU5F1P5 & $10 \mathrm{q} 21.3$ & NC_000010.11 & $659-1,583$ & $68,010,879-68,009,954$ & 925 & 88 \\
\hline POU5F1P3 & $12 \mathrm{p} 13.31$ & NC_000012.12 & $234-1,583$ & $8,133,523-8,134,873$ & 1,350 & 96 \\
\hline
\end{tabular}

${ }^{\mathrm{a}}$ Homology was assessed by BLAST searches of GenBank human genomic sequences using Oct3 cDNA (NM_001159542.1). POU5F1P, POU class 5 homeobox 1 pseudogene; POU5F1, POU class 5 homeobox 1; POU5F1B, POU class 5 homeobox $1 \mathrm{~B}$.

KY781167, which is expressed in breast tumors, uses the farthest $5^{\prime}$ exon and is initiated on chromosome 6 at position 31,186,202 in a sequence (LC050991.1) called psoriasis susceptibility 1 candidate 3 (PSORS1C3); it does not contain an ORF to encode an intact Oct4 isoform. KY781166, which is expressed in normal breast tissues, is a shorter DQ486515 5 region sequence with an important single-nucleotide polymorphism (SNP) that creates an 'ATG' translation initiation codon to encode a 265-aa Oct4B isoform (Table III and Fig. 3). All sequenced clones of the 5'-RACE product from normal breast tissues contain this SNP.

The genomic organization of the Oct 3 and Oct 4 genes is shown in Fig. 3A. Oct 3 is an intronless gene, whereas the Oct4 gene has $\geq 8$ exons. Specifically, the Oct4 gene has multiple transcription initiation sites in the exon ranging from sites $31,167,170$ to $31,165,926$. The last two exons are retained in all Oct4 transcript variants. The amino acid sequences of Oct3 (NP_001153014.1), Oct4 (NP_002692.2) and Oct4B (NP_001272916.1) are aligned in Fig. 3B. Oct4 has 360 amino acids and is one amino acid longer and $96 \%$ identical to Oct3. Oct4B consists of 265 amino acids, with its last 225 being the same as those of Oct4; it contains intact POU-S and POU-H domains.

\section{Discussion}

In the present study, all breast tumors examined, regardless of tumor type, expressed Oct3/4 mRNAs at levels 10- to 100-fold higher than those in normal breast tissues. Additionally, Oct3/4 protein expression in breast tumors was confirmed by western blot analysis and immunostaining. These observations are consistent with previous findings for normal breast and breast cancer cell lines $(8,12,22)$ as well as recent clinicopathological evaluations in which Oct $3 / 4$ expression was reported to be associated with poor clinical outcomes (20,29-31). However, Oct3/4 mRNA levels were not correlated with tumor type, tumor size, level of differentiation or estrogen/progesterone/ Her2 receptor status in this study, which is inconsistent with positive correlations between Oct 4 expression and breast cancer type (such as lymph node metastasis and histological grade) reported in other studies $(29,31)$. This discrepancy was likely due to the small number of tumor samples included in this study.

Notably and for the first time (to the best of our knowledge), the findings of the current study provided strong evidence that breast tumor and normal breast tissues express different Oct3/4 genes and transcripts. The 5'-RACE results revealed different Oct $3 / 4$ transcripts between breast tumors and MCF-7 cells and normal breast tissues and MCF-10A cells. These different RACE products are likely not RNA degradation products because 3'-RACE using the same RNAs only produced a single major product for each tissue and cell. Indeed, sequencing of the RACE products indicated that the different products resulted from expression of different genes, the use of different transcription initiation sites, or variable gene splicing. MCF-10A cells and normal breast tissues only expressed $P O U 5 F 1$ transcripts, though $\mathrm{MCF}-7$ cells and breast tumors expressed both $P O U 5 F 1 B$ and $P O U 5 F 1$ transcripts, with predominant $P O U 5 F 1 B$ expression in the former. The reason for the scant products and lack of $P O U 5 F 1 B$ transcripts in the 5'-RACE experiments with breast tumors was most likely due to the lower RNA amounts used in RACE conducted using tissues compared with that using cells (polyA ${ }^{+}$vs. total RNA). A single-nucleotide mismatch in the $159 \mathrm{R}$ primer used in the 5'-RACE for POU5F1B, which was realized following the experiment, may have also contributed to these results. Nevertheless, the 3'-RACE results demonstrated expression of $P O U 5 F 1 B$ and $P O U 5 F 1$ in tumor tissues. 
The possible differential expression of POU5F1 and $P O U 5 F 1 B$ in breast tumors and normal tissues warrants clearly distinguishing between these two genes. We previously proposed that the two sequences are two individual genes and designated POU5F1 as Oct4 and POU5F1B as Oct3 $(1,2)$, as was used in the present study. These designations are also supported by the following: i) The two sequences are located on different chromosomes, with POU5F1 on chromosome 6 and POU $F 1 B$ on chromosome 8; ii) POU5F1 has multiple exons and belongs to the POU-V family, whereas POU5F1B is intronless and belongs to the POU-III family (1); and iii) the Oct4 protein is one amino acid longer than and $4 \%$ different from the Oct 3 protein.

The present study identified multiple Oct 4 transcripts expressed in breast tissues and cells, displaying different transcription initiation sites and/or RNA splicing. Surprisingly, the Oct4 transcript (NM_002701) that encodes the major form of the Oct4 protein in ES cells (NP_002692, 360 aa) was not detected. The full-length cDNAs of the majority of the Oct 4 transcripts detected in this study were cloned (DQ486513-DQ486517). However, computational analysis of these cDNAs failed to identify an ORF that encodes an Oct4 protein with intact POU-S and POU-H domains, and no products were obtained when using these cDNAs in an in vitro transcription and translation assay, indicating that these transcripts are untranslatable. The putative Oct4 transcript obtained from normal breast tissues (KY781166) contains an SNP that creates an 'ATG' initiation codon from an 'AGG' and an ORF that can encode the 265-amino acid Oct4B protein. This SNP (reference no. 3130932; ncbi.nlm.nih.gov/ snp/) is also found in the Celera and GenBank human genome assemblies and may have important functional significance. Oct4B was not detected in normal breast tissues by western blot analysis (a limitation of our western blot analysis was the lack of a loading control to confirm there was protein in each lane) and immunohistological staining, which was likely to be because the protein levels were too low to be detected. In addition, there is evidence that Oct 4 transcripts can be translated using a downstream in-frame non-AUG (CUG) start codon to express a 190-amino acid isoform (Table III) or a downstream AUG start codon to express a 164- amino acid isoform (32). These isoforms were not detected in the in vitro transcription and translation assay in the present study. Nevertheless, even though these short isoforms are produced, they may not have any of the biological functions of Oct4 because they do not contain intact POU domains, which are required to efficiently bind to target gene DNA elements. Taken together, the data demonstrated that normal breast tissues express low levels of Oct4B, which may be functionally different from Oct4 due to the lack of a $5^{\prime}$ transactivation domain, whereas breast tumors express both Oct 3 and untranslated Oct 4 transcripts.

In addition to the high homology between the Oct4 and Oct 3 sequences [98\% identity between Oct4 mRNA (NM_002701) and Oct3 mRNA (NM_001159542)], the 3' sequences of Oct $3 / 4$ cDNAs also have high homology to the Oct $3 / 4$ pseudogenes $(25,26,33)$ on chromosomes $1,3,8$, 10 and 12 (Table IV). Expression of these pseudogenes has been observed in tumors and cells $(26,33)$. As a transcript from chromosome 1 (POU5F1P4) was amplified by 3'-RACE in this study, the primers used for analyzing Oct $3 / 4$ expression should not be designed based on Oct3/4 3' mRNA sequences. Indeed, only short 5' sequences should be used, but with caution, as the $5^{\prime}$ sequence is both Oct3/4 and isoform specific. It is important to note that because the majority of Oct 4 transcripts may not be translated or may not produce proteins with Oct4 biological functions, detection of Oct4 transcripts does not necessarily indicate Oct4 protein expression in tissues and cells.

Based on its aberrant expression in breast tumors, Oct $3 / 4$ is a potential prognostic marker for breast cancer. These data support the hypothesis that adult stem cells serve as targets for carcinogenesis $(34,35)$ due to the essential role of Oct4 in the regulation and maintenance of stem cell pluripotency and self-renewal (5). It has been demonstrated that Oct3/4expressing breast cancer stem cells isolated from breast cancer lesions exhibit stem/progenitor cell properties (36). Furthermore, because Oct4 is the most important among the four embryonic transcription factors that reprogram adult somatic cells into undifferentiated, pluripotent, and self-renewable states (referred to as induced pluripotent stem cells) $(1,37)$, aberrant expression of Oct $3 / 4$ in adult somatic cells may also induce tumorigenesis. Furthermore, expression of Oct3/4 may be required for the maintenance of transformed cancer cells. Thus, Oct $3 / 4$ may represent an excellent target for gene-directed therapeutic interventions for the prevention and treatment of breast cancer. In summary, the results of the current study suggest that Oct3, rather than Oct 4 , represents a potential prognostic marker and an excellent target for genedirected therapeutic interventions for breast cancer.

\section{Acknowledgements}

We thank Dr Timothy Hunter, Mr. Scott Tighe and Ms. Mary Lou Shane at the Vermont Cancer Center (Burlington, VT, USA) for their help with the DNA sequencing analysis.

\section{Funding}

This research was funded by the Department of Defense Breast Cancer Research Program Concept Award (grant no. W81XWH05-1-0432; to FQZ), the Vermont Cancer Center VCC/LCCRO Pilot Award (grant no. 022820; to FQZ), and the Vermont Genetics Network graduate assistantship (to YM).

\section{Availability of data and materials}

The datasets used and/or analysed during the current study are available from the corresponding author on reasonable request.

\section{Authors' contributions}

FQZ, YM, DBL, MPW, GZ, QT and KB performed the experiments. YM, DK, DW and JT were involved in the breast tumor and normal breast tissue collection. DWL performed the statistical analysis. FQZ wrote the manuscript. All authors have read and approved the manuscript.

\section{Ethics approval and consent to participate}

The study protocol was approved and the requirement for informed patient consent was waived by the Institutional Review Boards of the University of Vermont (no. M08-186). 


\section{Consent for publication}

Informed patient consent was waived by the Institutional Review Boards of the University of Vermont (no. M08-186).

\section{Competing interests}

The authors declare that they have no competing interests.

\section{References}

1. Zhao FQ: Octamer-binding transcription factors: Genomics and functions. Front Biosci 18: 1051-1071, 2013.

2. Qian X and Zhao FQ: Regulatory roles of Oct proteins in the mammary gland. Biochim Biophys Acta 1859: 812-819, 2016.

3. Schöler HR, Dressler GR, Balling R, Rohdewohld H and Gruss P: Oct-4: A germline-specific transcription factor mapping to the mouse t-complex. EMBO J 9: 2185-2195, 1990.

4. Niwa H, Miyazaki J and Smith AG: Quantitative expression of Oct-3/4 defines differentiation, dedifferentiation or self-renewal of ES cells. Nat Genet 24: 372-376, 2000.

5. Babaie Y, Herwig R, Greber B, Brink TC, Wruck W, Groth D, Lehrach H, Burdon T and Adjaye J: Analysis of Oct4-dependent transcriptional networks regulating self-renewal and pluripotency in human embryonic stem cells. Stem Cells 25: 500-510, 2007.

6. Pesce M and Schöler HR: Oct-4: Gatekeeper in the beginnings of mammalian development. Stem Cells 19: 271-278, 2001.

7. Pesce M and Schöler HR: Oct-4: Control of totipotency and germline determination. Mol Reprod Dev 55: 452-457, 2000.

8. Tai MH, Chang CC, Kiupel M, Webster JD, Olson LK and Trosko JE: Oct4 expression in adult human stem cells: Evidence in support of the stem cell theory of carcinogenesis. Carcinogenesis 26: 495-502, 2005

9. Gidekel S, Pizov G, Bergman Y and Pikarsky E: Oct-3/4 is a dose-dependent oncogenic fate determinant. Cancer Cell 4: 361-370, 2003.

10. de Jong J and Looijenga LH: Stem cell marker OCT3/4 in tumor biology and germ cell tumor diagnostics: History and future. Crit Rev Oncog 12: 171-203, 2006.

11. Monk M and Holding C: Human embryonic genes re-expressed in cancer cells. Oncogene 20: 8085-8091, 2001.

12. Jin T, Branch DR, Zhang X, Qi S, Youngson B and Goss PE: Examination of POU homeobox gene expression in human breast cancer cells. Int J Cancer 81: 104-112, 1999.

13. Chen Z, Xu WR, Qian H, Zhu W, Bu XF, Wang S, Yan YM, Mao F, Gu HB, Cao HL, et al: Oct4, a novel marker for human gastric cancer. J Surg Oncol 99: 414-419, 2009.

14. Iki K and Pour PM: Expression of Oct4, a stem cell marker, in the hamster pancreatic cancer model. Pancreatology 6: 406-413, 2006.

15. Saigusa S, Tanaka K, Toiyama Y, Yokoe T, Okugawa $\mathrm{Y}$, Ioue Y, Miki C and Kusunoki M: Correlation of CD133, OCT4 and SOX2 in rectal cancer and their association with distant recurrence after chemoradiotherapy. Ann Surg Oncol 16 3488-3498, 2009.

16. Li B, Yao Z, Wan Y and Lin D: Overexpression of OCT4 is associated with gefitinib resistance in non-small cell lung cancer. Oncotarget 7: 77342-77347, 2016.

17. Zhou J, Dong D, Cheng R, Wang Y, Jiang S, Zhu Y, Fan L, Mao X, Gui Y, Li Z, et al: Aberrant expression of KPNA2 is associated with a poor prognosis and contributes to OCT4 nuclear transportation in bladder cancer. Oncotarget 7: 72767-72776, 2016.

18. Asadi MH, Khalifeh K and Mowla SJ: OCT4 spliced variants are highly expressed in brain cancer tissues and inhibition of OCT4B1 causes $\mathrm{G} 2 / \mathrm{M}$ arrest in brain cancer cells. J Neurooncol 130: $455-463,2016$
19. Hochedlinger K, Yamada Y, Beard C and Jaenisch R: Ectopic expression of Oct-4 blocks progenitor-cell differentiation and causes dysplasia in epithelial tissues. Cell 121: 465-477, 2005.

20. Cai S, Geng S, Jin F, Liu J, Qu C and Chen B: POU5F1/Oct-4 expression in breast cancer tissue is significantly associated with non-sentinel lymph node metastasis. BMC Cancer 16: 175, 2016.

21. Wang D, Lu P, Zhang H, Luo M, Zhang X, Wei X, Gao J, Zhao Z and Liu C: Oct-4 and Nanog promote the epithelial-mesenchymal transition of breast cancer stem cells and are associated with poor prognosis in breast cancer patients. Oncotarget 5: 10803-10815, 2014.

22. Wang P, Branch DR, Bali M, Schultz GA, Goss PE and Jin T: The POU homeodomain protein OCT3 as a potential transcriptional activator for fibroblast growth factor-4 (FGF-4) in human breast cancer cells. Biochem J 375: 199-205, 2003.

23. McLeskey SW, Kurebayashi J,Honig SF, Zwiebel J, Lippman ME, Dickson RB and Kern FG: Fibroblast growth factor 4 transfection of MCF-7 cells produces cell lines that are tumorigenic and metastatic in ovariectomized or tamoxifen-treated athymic nude mice. Cancer Res 53: 2168-2177, 1993.

24. Kim RJ and Nam JS: OCT4 expression enhances features of cancer stem cells in a mouse model of breast cancer. Lab Anim Res 27: 147-152, 2011.

25. Pain D, Chirn GW, Strassel C and Kemp DM: Multiple retropseudogenes from pluripotent cell-specific gene expression indicates a potential signature for novel gene identification. J Biol Chem 280: 6265-6268, 2005.

26. Suo G, Han J, Wang X, Zhang J, Zhao Y, Zhao Y and Dai J: Oct4 pseudogenes are transcribed in cancers. Biochem Biophys Res Commun 337: 1047-1051, 2005.

27. Takeda J, Seino S and Bell GI: Human Oct3 gene family: cDNA sequences, alternative splicing, gene organization, chromosomal location, and expression at low levels in adult tissues. Nucleic Acids Res 20: 4613-4620, 1992.

28. Livak KJ and Schmittgen TD: Analysis of relative gene expression data using real-time quantitative PCR and the 2(-Delta Delta C(T)) Method. Methods 25: 402-408, 2001.

29. Gwak JM, Kim M, Kim HJ, Jang MH and Park SY: Expression of embryonal stem cell transcription factors in breast cancer: Oct 4 as an indicator for poor clinical outcome and tamoxifen resistance. Oncotarget 8: 36305-36318, 2017.

30. Kaufhold S, Garbán H and Bonavida B: Yin Yang 1 is associated with cancer stem cell transcription factors (SOX2, OCT4, BMI1) and clinical implication. J Exp Clin Cancer Res 35: 84, 2016.

31. Liu T, Sun B, Zhao X, Li Y, Gu Q, Dong X and Liu F: OCT4 expression and vasculogenic mimicry formation positively correlate with poor prognosis in human breast cancer. Int J Mol Sci 15: 19634-19649, 2014.

32. Wang X, Zhao Y, Xiao Z, Chen B, Wei Z, Wang B, Zhang J, Han J, Gao Y, Li L, et al: Alternative translation of OCT4 by an internal ribosome entry site and its novel function in stress response. Stem Cells 27: 1265-1275, 2009.

33. Zhao S, Yuan Q, Hao H, Guo Y, Liu S, Zhang Y, Wang J, Liu H, Wang F, Liu K, et al: Expression of OCT4 pseudogenes in human tumours: Lessons from glioma and breast carcinoma. J Pathol 223: 672-682, 2011.

34. Cotsarelis G, Sun TT and Lavker RM: Label-retaining cells reside in the bulge area of pilosebaceous unit: Implications for follicular stem cells, hair cycle, and skin carcinogenesis. Cell 61: 1329-1337, 1990.

35. Aguilar-Gallardo C and Simón C: Cells, stem cells, and cancer stem cells. Semin Reprod Med 31: 5-13, 2013.

36. Ponti D, Costa A, Zaffaroni N, Pratesi G, Petrangolini G, Coradini D, Pilotti S, Pierotti MA and Daidone MG: Isolation and in vitro propagation of tumorigenic breast cancer cells with stem/progenitor cell properties. Cancer Res 65: 5506-5511, 2005.

37. Takahashi K, Tanabe K, Ohnuki M, Narita M, Ichisaka T, Tomoda K and Yamanaka S: Induction of pluripotent stem cells from adult human fibroblasts by defined factors. Cell 131: 861-872, 2007 